\title{
Fe-Oxide Nanomaterial: Synthesis, Characterization and Lead Removal
}

\author{
Buzuayehu Abebe*, H. C. Ananda Murthy \\ Department of Applied Chemistry, School of Applied Natural Sciences, Adama Science and Technology University, \\ Adama, Ethiopia \\ Email: ^buzea8@gmail.com
}

How to cite this paper: Abebe, B. and Murthy, H.C.A. (2018) Fe-Oxide Nanomaterial: Synthesis, Characterization and Lead Removal. Journal of Encapsulation and Adsorption Sciences, 8, 195-209. https://doi.org/10.4236/jeas.2018.84010

Received: July 12, 2018

Accepted: November 16, 2018

Published: November 19, 2018

Copyright ( 92018 by authors and Scientific Research Publishing Inc. This work is licensed under the Creative Commons Attribution International License (CC BY 4.0).

http://creativecommons.org/licenses/by/4.0/

cc) (7) Open Access

\begin{abstract}
Organic solvent free iron oxide nanomaterial used for lead removal was synthesized by co-precipitation method. Fourier transform infrared spectroscopy (FT-IR), scanning electron microscopic with energy dispersive X-ray analysis (SEM-EDX), X-ray diffraction (XRD) and thermo gravimetric-differential thermal (TG-DTA) analysis were used to determine the surface characteristics and analysis of iron oxide. Optimization of solution $\mathrm{pH}$, adsorbent dosage, contact time, agitation speed and initial lead ion concentration were conducted for further adsorption isotherm, kinetics, thermodynamics and desorption study. Langmuir sorption isotherm model fits the adsorption data better than Freundlich, Dubinin-Radushkevich (D-RK) and Flory-Huggins (FH) models. The mean adsorption energy and free energy obtained from D-RK and FH models guides that the mechanism was under control of physical adsorption and actuality of spontaneous reaction, respectively. From kinetics of adsorption pseudo second (PSO) model fits well than pseudo first (PFO) and Elovich adsorption-reaction models. And to test whether the reaction is under control of adsorption-diffusion or not the intra particle diffusion (IPD) model was tested, but it fails to pass through the origin. This indicates that the reaction mechanism only under control of adsorption-reaction. The maximum adsorption capacity $\left(q_{\max }\right)$ of the adsorbent was $70.422 \mathrm{mg} / \mathrm{g}$.
\end{abstract}

\section{Keywords}

Nano-Iron Oxide, Sorption Isotherm, Kinetics, Thermodynamics, Lead Desorption

\section{Introduction}

Heavy metals are the major cause of water pollution. Among many hazardous 
toxic heavy metals which cause significant health risks for human, lead stands on the second [1] [2]. Hence, there is a need for the development of simple and cost effective methods to remove it. The most familiar methods for the effective removal of heavy metals from waste waters include precipitation, ion exchange, membrane filtration, electrochemical technologies and adsorption. Among many such methods, adsorption is the best choice as it offers easy operation and the regeneration of the adsorbents with desorption processes for multiple use.

Heavy metals remediation has been efficiently accomplished in the past by several nano metal oxides, including: ferric oxides, manganese oxides, aluminum oxides, titanium oxides, magnesium oxides and cerium oxides [3]. This could be attributed to large surface areas and high activities caused by the size quantization effect in nanoparticles [4]. Of those ferric oxides nanomaterials hae gained increased attentions because of the ease of regeneration of iron oxides using magnetic field; after regeneration it is possible to use it reputedly. Such easy regeneration is important to improve the operation efficiency and decrease the cost during treatment of water/wastewater [5]. In addition to this nano-sized ferric oxides have been proved to be the first adsorbents for toxic metal sorption which is possibly due to their large surface area [6] [7]. And it can be used directly to contaminated areas with insignificant dangers of secondary contamination [8]. The past studies revealed the existence of various forms of ferric oxides in nano-sized iron oxide for heavy metals removal from water/wastewater includes, amorphous hydrous iron oxides, hematite $\left(\alpha-\mathrm{Fe}_{2} \mathrm{O}_{3}\right)$, goethite $(\alpha-\mathrm{FeOOH})$, maghemite $\left(\gamma-\mathrm{Fe}_{2} \mathrm{O}_{3}\right)$ and magnetite $\left(\mathrm{Fe}_{3} \mathrm{O}_{4}\right)$ [9] [10].

The synthesis routes of metal oxides nano materials include gas phase deposition, electron beam lithography, pulsed laser ablation, laser induced pyrolysis, powder ball milling, aerosol from physical methods and reverse micelle (or micro-emulsion), sol-gel, co-precipitation, hydrothermal, electrochemical deposition, sonochemical, thermal decomposition, gas-phase reduction from chemical methods [11]. Among all the synthetic methods, co-precipitation [12], thermal decomposition and/or reduction [13] and hydrothermal synthesis [14] methods were widely used and are easily scalable with high yields. The main draw backs of previous studies were the use of toxic organic solvents. In this context, ongoing research has modified the existing different techniques by using only water as solvent.

For this work co-precipitation has been used for synthesis of the adsorbent by using only distilled water as a solvent. The main objective of this study was to synthesize and characterize the as-synthesized materials using different analytical techniques (FT-IR, XRD, SEM-EDX and TGA-DTA) and to evaluate its adsorption efficiency for the removal of lead ions from aqueous solution. For this study the mechanism of the adsorption was evaluated with the help of Langmuir, Freundlich, D-RK and FH adsorption isotherm models. Moreover to check the kinetics of adsorption PFO, PSO and Elovich models were used for adsorption-reaction and IPD model were used for adsorption-diffusion. 


\section{Methods}

\subsection{Synthesis of Nano Sized Iron Oxide}

All the chemical/reagent used for the current investigation was analytical grade and only distilled water was used as a solvent. Nano-sized Fe oxide was prepared by co-precipitation method using iron (III) nitrate Nonahydrate $\left[\mathrm{Fe}\left(\mathrm{NO}_{3}\right)_{3} \cdot 9 \mathrm{H}_{2} \mathrm{O}\right]$ salt as precursor and cetyltrimethyl ammonium bromide (CTAB) as a precipitating agent. The respective ratio used during mixing of precursor and precipitating agent was 8:1 with continuous stirring on magnetic stirrer. Sodium borohydride was then added as reducing agent. The $\mathrm{pH}$ of the solution was adjusted to 12 by drop wise addition of acid and base. The solution was refluxed at $100^{\circ} \mathrm{C}$ for 2 hours with constant stirring. The obtained precipitate was then separated from solution using centrifuge. After washing the precipitate was washed with alcohol and water, it was dried in oven over night at a temperature of $105^{\circ} \mathrm{C}$ and finally the dry powder was calcined at $450^{\circ} \mathrm{C}$ for two hour.

\subsection{Batch Adsorption Experiments}

The sorption test was conducted in $50 \mathrm{~mL}$ erlenmeyer flasks containing adsorbent to solution ratio of 0.5:300 [0.05 g of iron oxide: $30 \mathrm{~mL}$ of $45 \mathrm{mg} / \mathrm{L}$ of $\left.\mathrm{Pb}\left(\mathrm{NO}_{3}\right)_{3}\right]$. The $\mathrm{pH}$ of the solution was adjusted with the help of dilute $\mathrm{HCl}$ and $\mathrm{NaOH}$ solution. Equilibration of the experiments was done on a rotary shaker. The amount of lead adsorbed was known by the differences in equilibrium and initial lead concentration. Atomic adsorption spectrometer (AAS) was used for quantitative estimation of lead. The samples containing more lead ion than the highest concentration of detection limit of the instrument were diluted and the dilution factor was compensated during final calculation. The $\mathrm{pH}$, adsorbent dose, agitation speed, contact time and initial lead ion concentration were optimized during experimentation [15].

From mass balance for the adsorbate in the glass ware is:

$$
m\left(q-q_{e}\right)=\left(C_{o}-C_{e}\right) V
$$

From which a relationship between value of $\mathrm{C}$ and the corresponding equilibrium value of $q$ can be established. To determine equilibrium relationship $q_{o}$ become equal to zero $\left(q_{o}=0\right)$,

$$
q_{e}=\left(C_{o}-C_{e}\right) \times V / m
$$

The percent of adsorption (\%) were calculated using equation:

$$
\%=\left(C_{o}-C_{e}\right) / C_{o} \times 100
$$

where: $C_{o}=$ initial concentrations $(\mathrm{mg} / \mathrm{L})$ and $C_{e}=$ equilibrium concentrations $(\mathrm{mg} / \mathrm{L})$ of lead ion, $q_{e}=$ adsorption capacity of adsorbent $(\mathrm{mg} / \mathrm{g}), V=$ volume of reaction mixture $(\mathrm{L}), m=$ mass of adsorbent $(\mathrm{g})$.

\subsection{1. pH Optimization}

To optimize the effect of $\mathrm{pH}$ on the lead sorption, $0.1 \mathrm{~g}$ of the sorbent was added into $50 \mathrm{~mL}$ erlenmeyer flask containing $30 \mathrm{~mL}$ of $45 \mathrm{mg} / \mathrm{L}$ lead ions, then by va- 
rying the $\mathrm{pH}$ of the solutions from 1 - 11 with two increments and keeping the other conditions at constant value (rotation speed of $120 \mathrm{rpm}$ and contact time $130 \mathrm{~min}$.) the optima were obtained.

\subsubsection{Dose Optimization}

Adsorbent dosage was evaluated and optimized by taking various amounts of adsorbent dose as, $0.01,0.03,0.05,0.1,0.2$ and $0.4 \mathrm{~g}$, while the other parameters were kept at constant value and $\mathrm{pH}$ was maintained at the optimized value of 9 .

\subsubsection{Agitation Speed Optimization}

The effect of agitation speed was optimized by varying the speed of rotary shaker to $30,90,120,150,180$ and $200 \mathrm{rpm}$. During here during optimization dosage and $\mathrm{pH}$ were kept at optimized value and initial lead concentration at constant value.

\subsection{Adsorption Isotherms and Kinetics of Adsorption}

The degree of affinity of the adsorbate towards adsorbent is quantified using adsorption isotherms. A number of isotherms have been developed to describe equilibrium relationships. Here Langmuir, Freundlich, D-RK and FH models were engaged to describe the experimental results of lead sorption. Sorption isotherms experiment was done again by keeping all parameters at optimized values and by varying lead ion concentration as: $25,45,65,85,105$ and $125 \mathrm{mg} / \mathrm{L}$ in separate $50 \mathrm{~mL}$ erlenmeyer flask. And the study of kinetics was conducted by taking various contact time 10, 50, 90, 130, 170, 210 and 240 minutes under optimized values of $\mathrm{pH}$, adsorbent dose, agitation speed and lead ion concentration.

\subsection{Thermodynamics Study}

In order to determine the effect of temperature on sorption phenomenon, all predetermined and optimized values of parameters were used and the temperature established during sorption was varied from $25^{\circ} \mathrm{C}$ to $55^{\circ} \mathrm{C}$ with increment of $10^{\circ} \mathrm{C}$.

\subsection{Reproducibility Studies}

Lead ions desorption studies were done using lead ions loaded powder sample which is obtained after adsorption of lead ions on powder using all optimized values. $0.05 \mathrm{~g}$ of iron oxides of lead loaded powder was added into flasks containing $30 \mathrm{~mL}$ of double deionized water. $0.1 \mathrm{M} \mathrm{NaOH}$ and $0.1 \mathrm{M} \mathrm{HCl}$ solutions were used to adjust $\mathrm{pH}$ of the solution to: $1,3,5,7,9$ and 11. After agitation the filtered solution were analyzed for desorbed lead ions concentration.

\section{Result and Discussion}

\subsection{XRD}

The as-synthesized iron oxide nanoparticle which is examined by XRD tech- 
nique was given in Figure 1(a). The obtained approximate crystalline size of the nano particle was $16.55 \mathrm{~nm}$. to calculate the size of the particle Debye Scherer equation were used, $D=K \lambda / \beta \cos \theta$; were $D$ is the mean size, $K$ is constant (0.94), $\lambda$ is wavelength of X-ray $(0.15506 \mathrm{~nm}), \beta$ is excess line of broadening and $\theta$ is Bragg angle, $\beta=G-g$, were $G$ is the line width (in radians) and $g$ is instrument line broadening (in radians) [16]. All peaks on diffraction pattern spectrum confirm the structure to be rhombohedral $\alpha-\mathrm{Fe}_{2} \mathrm{O}_{3}$ in comparison other results [17]. Width of the peaks confirms the low particle size or high surface area to low volume ratio values, but, the low strength of peaks reveals that the as-synthesized nano-materials may not be fully crystalline. The $2 \theta$ values and the respective planes were found to be, 24.42 (012), 33.44 (104), 35.78 (110), 41.28 (113), 49.82 (024), 54.39 (116), 57.55 (018), 62.82 (214) and 64.46 (300) [18] [19].

\subsection{SEM-EDX}

SEM (Model ZEISS EVO 18 with INCA software for quantitative Analysis) is another useful tool for the morphological analysis of the surface of solids. The images of as-synthesized nano material with different magnification are as shown in Figure 1(b). These images confirm the presence of round shaped iron oxide nanoparticles. EDX proves that the presence of iron $(\mathrm{Fe})$, oxygen $(\mathrm{O})$ and carbon (C). The appearance of carbon on EDX was from standard used during analysis and the weight percent and atomic percent of the element are given on the spectrum. Except, Fe and O, no other elements were found in the spectrum.

\subsection{FT-IR}

The FTIR (Bruker IFS120 M Perkin Elmer) spectrum (Figure 1(c)) reveals strong bonding interaction between $\mathrm{Fe}$ and $\mathrm{O}$ in iron oxides nanoparticles. The broad vibrational peaks observed at 3400 and $1620 \mathrm{~cm}^{-1}$ corresponds to normal vibrations of water (H-O-H) and hydroxyl groups $(\mathrm{O}-\mathrm{H})$ absorbed on the surface, respectively [15]. The peaks at 478 and $544 \mathrm{~cm}^{-1}$ are due to bending vibration of Fe-O and Fe-O-Fe [20]. The other appeared peaks may be due to solvents used during synthesis.

\subsection{TGA-DTA}

The result of stability test of the as-synthesized iron oxide nanomaterial which is done by TG-DTA (DTG-60H) instrument is shown in Figure 1(d). Thermogravimetric analysis indicates two different weight losses observed at around 258 and $660^{\circ} \mathrm{C}$. It was observed that only $0.255 \mathrm{mg}$ of nanosorbent was lost out of $11.749 \mathrm{mg}$, therefore, the stability of iron oxides is believed to be good.

\subsection{Optimization}

The effect of $\mathrm{pH}$, adsorbent dose, speed of agitation and contact time on the lead ion sorption efficiency of nanosorbent is presented in the Figure 2. 


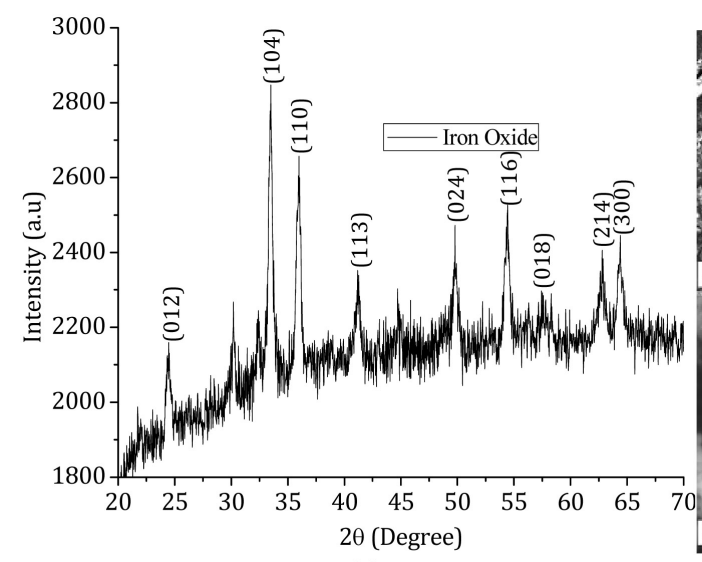

(a)

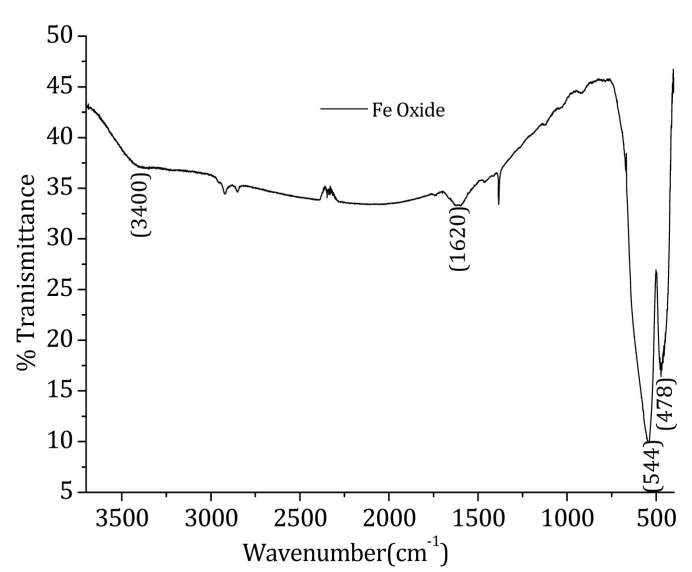

(c)

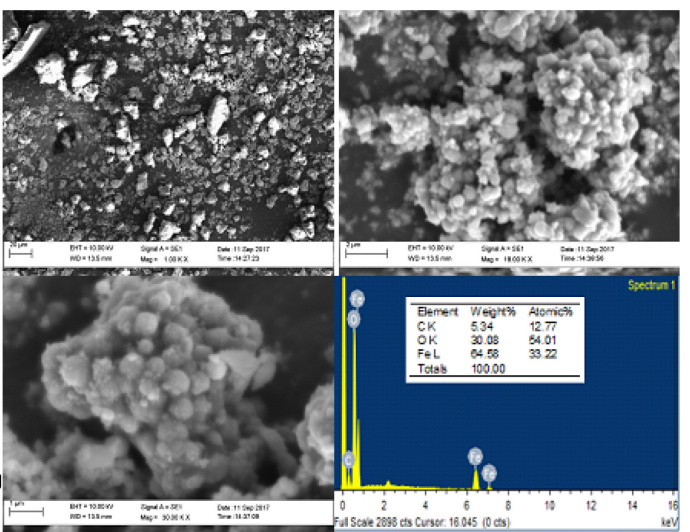

(b)
Figure 1. (a) XRD (b) SEM images at different magnification and EDX spectra (c) FT-IR spectrum (d) TG-DTA Thermogram of iron oxide calcined at $450^{\circ} \mathrm{C}$.

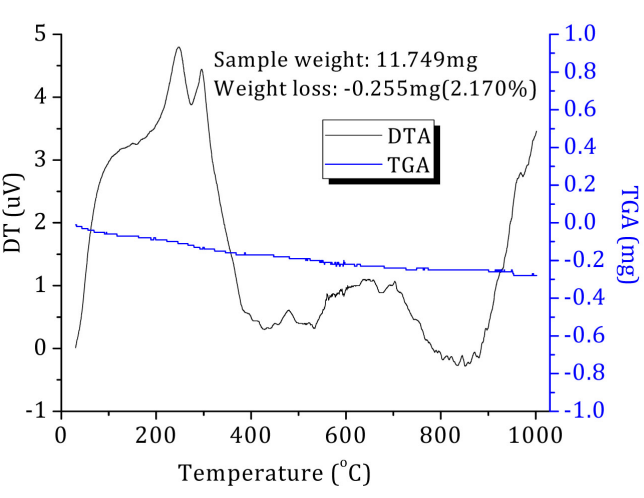

(d)

On $\mathrm{pH}$ optimization it was observed that greatest lead ion adsorption occurred under basic condition and the optimum $\mathrm{pH}$ value for sorption was found to be 9 as revealed by $\mathrm{pH}$ verses \% of sorption plot (Figure 2(a)). The lead removal from the solution increased with $\mathrm{pH}$, because increasing solution $\mathrm{pH}$ favors the de-protonation of nano sorbent surface, and this leads to increasing the negatively charged sites and hence the electrostatic forces of attraction between lead ions and the adsorbent increases. On lowering the $\mathrm{pH}$, it has been reported that competitive adsorption occurs between the competing metal ions and $\mathrm{H}^{+}$ ions in the solution [21]. The optimum dosage value was determined to be $0.2 \mathrm{~g}$ (Figure 2(b)) and beyond this value, the rises in amount of adsorbent dosage give no significant role on adsorption due to less availabilities of adsorbate and also it may be due to the formation of agglomeration between the particles. The agitation speed optimization that assists in diffusion of lead ion to adsorbent was shown in Figure 2(c); the obtained optimum point was at $90 \mathrm{rpm}$. After the optima, the decreasing behavior of the plot shows desorption of lead ions from physically adsorbed surface due to increase of agitation speed. The optimum value of contact time obtained was 170 minutes (Figure 2(d)); after the optimum 


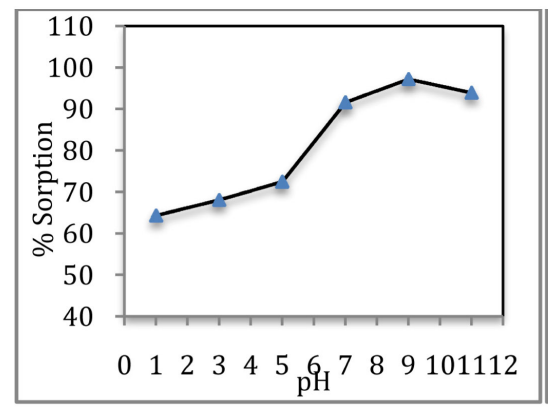

(a)

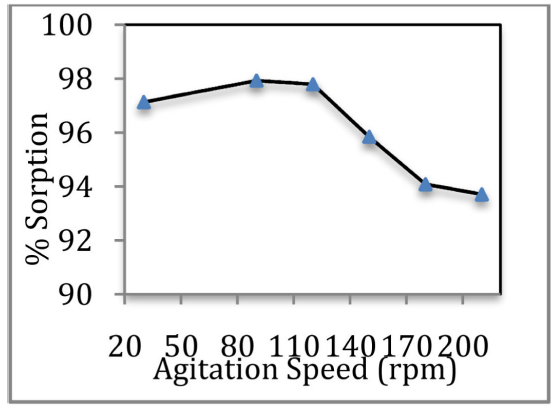

(c)

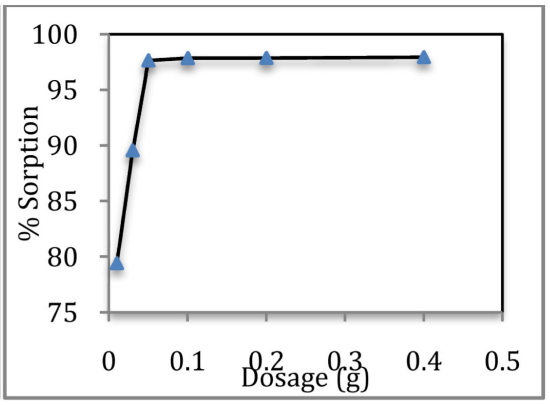

(b)

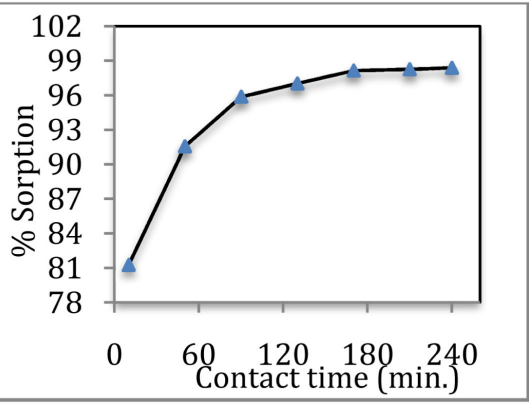

(d)

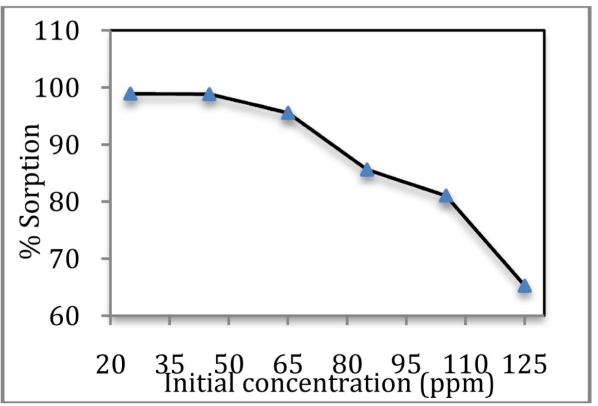

(e)

Figure 2. (a) Effect of pH (b) adsorbent dose (c) speed of agitation (d) contact time (e) initial lead ion concentration on adsorption of lead ion by iron oxide.

point since the adsorbent sites almost occupied it becomes constant. Short adsorption time for iron oxide based nano-adsorbents may possibly due to porosity of the adsorbent.

\subsection{Adsorption Isotherms}

The effect of initial concentration on lead ion uptake shows almost constant flow up to optimum value (45 mg/L) (Figure 2(e)) for two hours [19]. This trend is possibly due to the availability of active sites which gradually decreases as those sorption sites were used up and it prevents more ion adsorption by adsorbent specially if Langmuir isotherm model is the controlling mechanism [22]. The lead ion adsorption efficiency by the nanosorbent in terms of percentage at optimum point was found to be $98.86 \%$.

The linear Langmuir equation is as given below:

$$
C_{e} / q_{e}=1 / b q_{\max }+C_{e} / q_{\max }
$$


The significant characteristics of a Langmuir isotherm can be expressed in terms of a constant separation factor or equilibrium parameter, $R_{L}$ :

$$
R_{L}=1 /\left(1+b C_{o}\right)
$$

The linear Freundlich equation expressed as:

$$
\log q_{e}=\log K_{f}+1 / n \log C_{e}
$$

The linear Dubinin-Radushkevich equation:

$$
\ln q_{e}=\ln q_{s}-\beta \varepsilon^{2}, \text { where } \varepsilon=R T \ln \left(1+\frac{1}{C_{e}}\right) \text { and } E=\frac{1}{\sqrt{2 \beta}}
$$

The linear Flory-Huggins equation:

$$
\ln \left(\frac{\theta}{C_{o}}\right)=\ln k_{F H}+n \ln (1-n) \text { and } \Delta G^{o}=R T \ln \left(k_{F H}\right)
$$

where, $C_{o}=$ initial adsorbate concentration in solution $(\mathrm{mg} / \mathrm{L}), C_{e}=$ adsorbate equilibrium concentration in solution, $q_{o}=$ initial amount of adsorbate per unit mass of adsorbent (mg/g), $q_{e}=$ amount of adsorbate accumulated per gram of the adsorbent material, $q_{\max }=$ maximum uptake corresponding to the site saturation, $b=$ ratio of adsorption and desorption rates, $K_{f}=$ distribution coefficient and represents the quantity of adsorbate adsorbed onto adsorbent for unit equilibrium concentration, $1 / n=$ an empirical constant related to the magnitude of the adsorption or surface heterogeneity, $\theta\left(1-C_{e} / C_{o}\right)$ is Fractional coverage, $\varepsilon$ = Dubinin - Radushkevich isotherm constant and $q_{s}$ is saturation capacity $(\mathrm{mg} / \mathrm{g}), \beta$ is the constant related to free energy, $\mathrm{n}$ is the number of ions occupying adsorption sites, $T$ absolute temperature $(k)$ and $R$ is the universal gas constant $(8.314 \mathrm{~J} / \mathrm{molK})$. From sorption isothermal studies, the obtained sorption parameters given in Table 1 were calculated from the slopes and intercept of the linearized Langmuir (Figure 3(a)) and Freundlich plot (Figure 3(b)), D-RR (Figure 3(c)) and FH (Figure 3(d)) adsorption isotherm model. The correlation coefficient of Langmuir sorption isotherm model is much higher than the other models, which show that, Langmuir sorption isotherm model fits the sorption data better. The $R_{L}$ value indicates the type of the isotherm to be unfavorable if $R_{L}>1$, linear if $R_{L}=1$, irreversible if $R_{L}=0$ or favorable if $R_{L}<1$ [23]. The $R_{L}$ values for all concentration were found to lie between 0 and 1 indicates favorable sorption. The value of $1 / n$ being in between 0 and 1 on Freundlich model indicates the heterogeneity of the surface, to be more heterogeneous its value should be closer to zero. The value of $1 / n$ for this study is 0.352 not as such closer to zero, so the sorption mechanism deviates more towards Langmuir adsorption. The magnitude of $n$ being in between 2 - 10 confirms the favorability of sorption process and if its value is below 1 becomes chemical adsorption and if it is greater than one become physical [24]. Being values of $n$ for this study 2.86 states the reaction was under control of physical adsorption.

From D-RK model the calculated mean adsorption energy, $E$ was $1.89 \mathrm{KJ} / \mathrm{mol}$, being its value less than $8 \mathrm{KJ} / \mathrm{mol}$ specifies the domination of physical interaction. 
Table 1. Adsorption isotherm constants of different models for lead ion adsorption.

\begin{tabular}{ccccccccccc}
\hline Sorbent & \multicolumn{3}{c}{ Langmuir model } & \multicolumn{4}{c}{ Freundlich model Dubinin-Radushkevich } & \multicolumn{2}{c}{ Flory-Huggins } \\
\hline Fe-Oxide & $q_{\max }(\mathrm{mg} / \mathrm{g})$ & $b$ & $R_{L}$ & $K_{f}$ & $1 / n$ & $E(\mathrm{~kJ} / \mathrm{mol})$ & $\beta$ & $n$ & $\Delta G(\mathrm{~kJ} / \mathrm{mol})$ \\
\hline & 70.42 & 0.57 & 0.038 & 26.06 & 0.35 & 1.89 & -0.14 & -1.28 & -21.36 \\
\hline
\end{tabular}

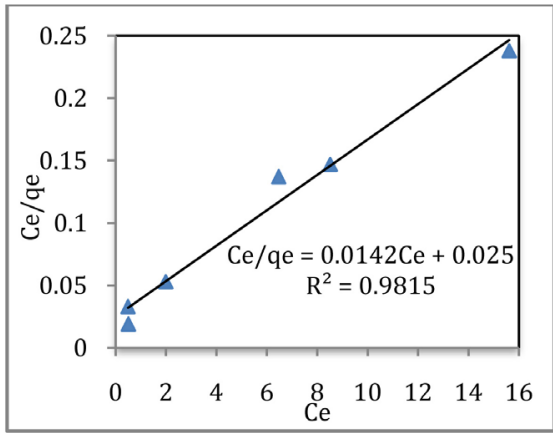

(a)

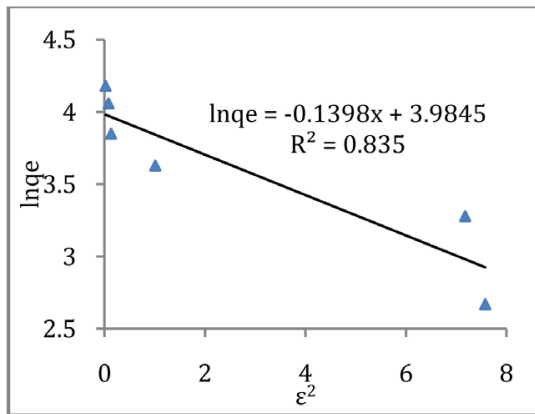

(c)

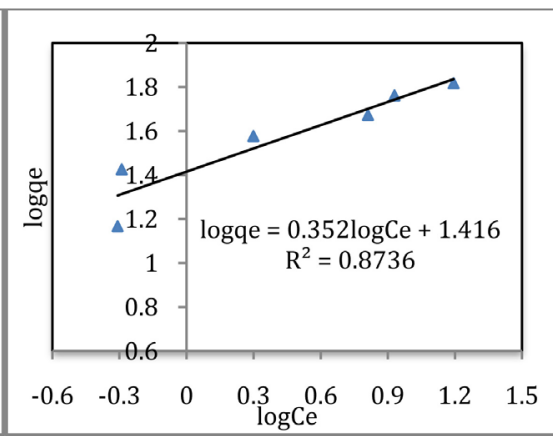

(b)

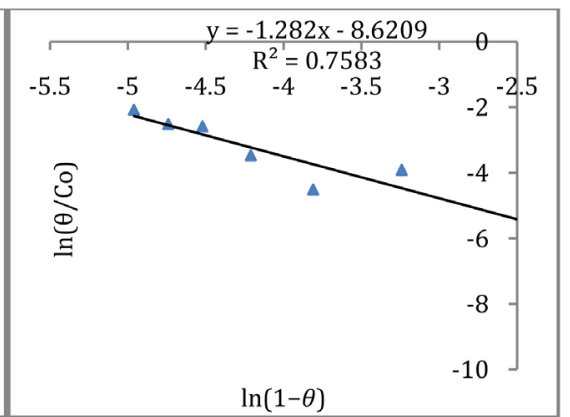

(d)

Figure 3. (a) Langmuir; (b) Freundlich; (c) Dubinin-Radushkevich; (d) Flory-Huggins adsorption isotherm of lead ion on Fe oxidesadsorbent.

And from FH model the obtained values for free energy, $\Delta G$ was -21.36 $(\mathrm{kJ} / \mathrm{mol})$, this shows that the spontaneity of the reaction [25] [26]. The obtained maximum sorption capacity $\left(q_{\max }\right)$ for the sorbent is $70.422 \mathrm{mg} / \mathrm{g}$.

\subsection{Kinetics of Sorption}

The result of kinetics of sorption study obtained after optimization of all parameters is shown in Figures 4(a)-(d). And the results of kinetics study and kinetics constants values are given in Table 2. From different kinetic models used to interpret the time dependent experimental data, the linear equation of the PFO, PSO, Elovich and IPD equations were used and the respective equation become as follows:

PFO:

$$
\log \left(q_{e}-q_{t}\right)=\log q_{e}-K_{1} t / 2.303
$$

PSO:

$$
t / q_{t}=1 / K_{2} q_{e}^{2}+t / q_{e}
$$

Elovich: 
Table 2. Kinetic parameters and correlation coefficient values of different kinetic models.

\begin{tabular}{cccccccccccccc}
\hline Metal & & \multicolumn{3}{c}{ Pseudo-1 ${ }^{\text {st }}$-order } & \multicolumn{3}{c}{ Pseudo-2 ${ }^{\text {nd }}$-order } & \multicolumn{3}{c}{ Intra-particle diffusion } & \multicolumn{2}{c}{ Elovich } \\
\hline & $q_{e}^{*}(\mathrm{mg} / \mathrm{g})$ & $K_{1}$ & $q_{e}^{* *}(\mathrm{mg} / \mathrm{g})$ & $R^{2}$ & $K_{2}$ & $q_{e}^{*}(\mathrm{mg} / \mathrm{g})$ & $R^{2}$ & $k_{\mathrm{i}}$ & $R^{2}$ & $C$ & $\beta$ & $R^{2}$ \\
\hline $\mathrm{Pb}(\mathrm{II})$ & 26.68 & 0.019 & 5.32 & 0.9835 & 0.01 & 27.17 & 0.999 & 0.37 & 0.887 & 21.61 & 0.65 & 0.983 \\
\hline
\end{tabular}

${ }^{*}$ calculated value and ${ }^{* *}$ experimental value.

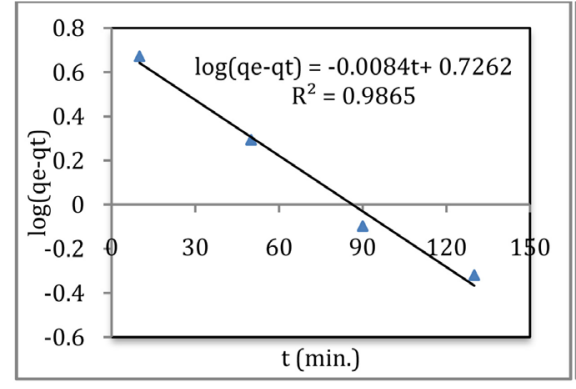

(a)

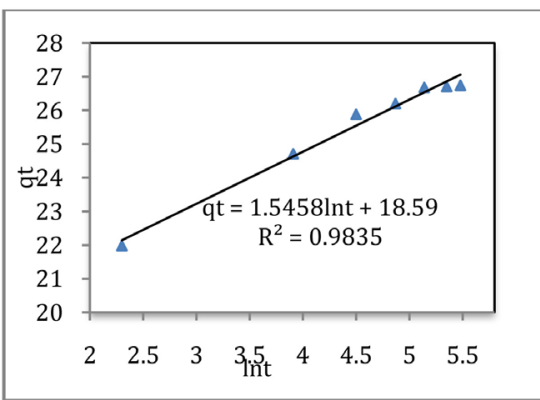

(c)

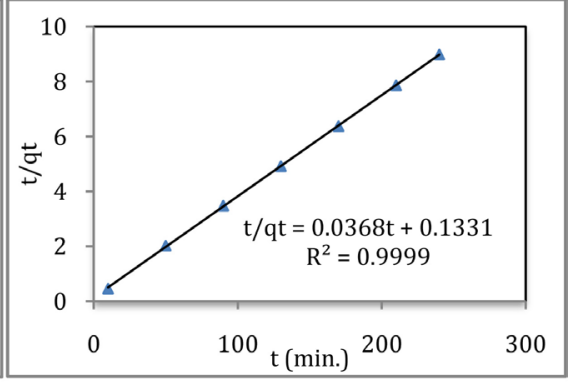

(b)

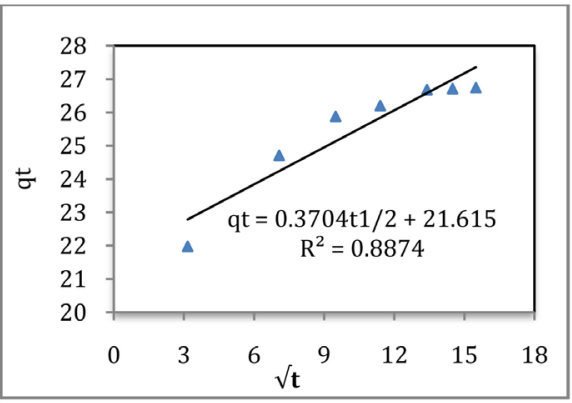

(d)

Figure 4. (a) PFO (b) PSO (c) Elovich (d) IPD kinetics model on removal of Pb(II) by Fe oxide.

$$
q_{t}=(1 / \beta) \ln (\alpha \beta)+(1 / \beta) \ln t
$$

Weber-Morris IPD model:

$$
q_{t}=k_{i} t^{1 / 2}+C
$$

where, $q_{e}$ and $q_{t}$ are the amounts of adsorbate adsorbed on the adsorbent at equilibrium and at various times $t(\mathrm{mg} / \mathrm{g})$, respectively, $k_{1}$ is the rate constant of the FSO model for the adsorption process $\left(\mathrm{min}^{-1}\right), k_{2}$ is the rate constant for the PSO model (mg/gmin, $\alpha$ is the initial sorption rate ( $\mathrm{mol} / \mathrm{g} \cdot \mathrm{min})$ and $\beta$ is the desorption constant $(\mathrm{g} / \mathrm{mol})), k_{i}$ is the IPD rate constant $\left(\mathrm{mg} / \mathrm{g} \cdot \mathrm{min}^{1 / 2}\right)$.

The plot of $\log \left(q_{e}-q_{t}\right)$ verses $t$ from PFO (Figure $\left.4(\mathrm{a})\right)$ and $t / q_{t}$ versus $t$ from PSO model were used to determine the respective $k_{1}$ and $K_{2}$ rate constant from the slopes and intercept (Figure $4 \mathrm{~b}$ ).

Depending on $R^{2}$ values relatively, PSO models adequately described the kinetics of sorption of lead ion better than others model, and its theoretical equilibrium capacity of $26.68 \mathrm{mg} / \mathrm{g}$ fit well with experimental data value of 27.17 $\mathrm{mg} / \mathrm{g}$, but not for PFO. Elovich model which is useful model in describing the chemisorption behavior of adsorbate-adsorbent interaction gives comparatively 
less $R^{2}$ values (Figure 4(c)). Regression coefficient value of intra-particle diffusion plots clearly demonstrates its deviation from linearity. To say the reaction is under the control of IPD the line should pass through the origin, unlike that of obtained result on this paper (Figure 4(d)). Therefore, possible to deduce that the reaction is totally under control of surface/adsorption-reaction mechanism, this indicates that the rate determining step become adsorption-reaction interaction instead of adsorption-diffusion [27] [28].

\subsection{Thermodynamics}

The effects of temperature on lead ion sorption are shown in Figure 5(a). The thermodynamic parameters $(\Delta G, \Delta H$ and $\Delta S)$ can be calculated by using the following equation:

$$
\begin{gathered}
\Delta G=-R T \ln K_{c} \\
\ln K_{c}=-\Delta H^{\mathrm{o}} / R T+\Delta S^{\mathrm{o}} / R \\
\Delta G^{\mathrm{o}}=\Delta H^{\mathrm{o}}-T \Delta S^{\mathrm{o}}
\end{gathered}
$$

where $R(8.314 \mathrm{~J} / \mathrm{mol} \cdot \mathrm{K})$ is the gas constant, $T(\mathrm{~K})$ is the absolute temperature and $K_{\mathrm{c}}$ is the standard thermodynamic equilibrium constant which is defined by $q_{e} C_{e^{*}}$

By plotting the graph of $\ln K_{\mathrm{c}}$ versus $T^{-1}$, the value of $\Delta H^{\circ}$ and $\Delta S^{\circ}$ can be estimated from the slopes and intercept. The obtained values of $\Delta G^{\circ}, \Delta H^{\circ}$ and $\Delta S^{\circ}$ different temperature were given in Table 3. The sorption rate for $\mathrm{Pb}(\mathrm{II})$ ions was found to increase with increase in the temperature due to increase in the surface area of adsorbent and diffusion of it. Consequently, the numbers of sites were found to increase because of the breaking of domestic bonds which in turn increases lead ions adsorption from aqueous solution. The decrease of $\Delta G$ values with the increasing temperature shows that the sorption was favorable at higher temperature. The positive values of $\Delta H$ indicates the endothermic nature of $\mathrm{Pb}$ (II) sorption process. The positive values of $\Delta S$ show that lead ions in liquid phase (aqueous solution) exhibits more disordered distribution than that in relatively ordered state of solid phase and during adsorption the solid-liquid interface become more random [29].

\subsection{Reproducibility Studies}

The reusability of the adsorbent after its repeated usage has been a crucial factor for economic compatibility. From the reproducibility/desorption studies (Figure 5(b)),

Table 3. Thermodynamic parameters for lead ion sorption.

\begin{tabular}{cccc}
\hline$T(\mathrm{~K})$ & $\Delta G(\mathrm{~kJ} / \mathrm{mol})$ & $\Delta H(\mathrm{~kJ} / \mathrm{mol})$ & $\Delta S(\mathrm{~J} / \mathrm{molK})$ \\
\hline 298 & -9.612 & 19.19 & \\
308 & -10.603 & & \\
318 & -11.593 & \\
328 & -12.584 & \\
\hline
\end{tabular}




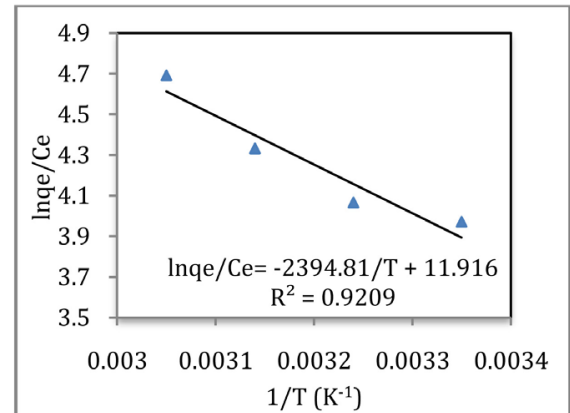

(a)

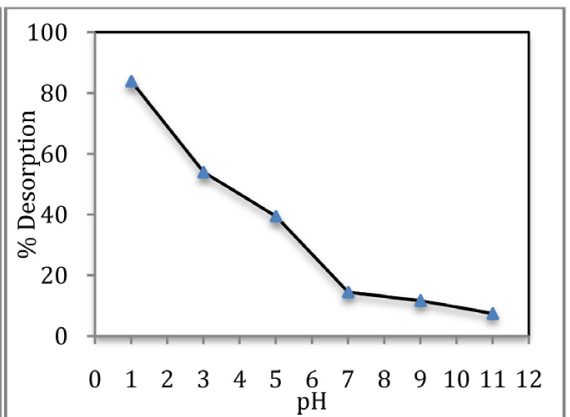

(b)

Figure 5. (a)Thermodynamics; (b) Effect of $\mathrm{pH}$ on desorption of lead.

the amount of desorption of lead ion decreases as the $\mathrm{pH}$ of solution increases. 83.94\% of $\mathrm{Pb}(\mathrm{II})$ ions was removed in the first cycle. Desirability was obtained using equation:

$$
\% \text { Desorption Efficiency }=D / A \times 100
$$

where, $D=$ Desorbed is the concentration of lead ion after the desorption process and $A=$ Adsorbed is $\left(C_{o}-C_{e}\right)$ for each recovery process.

\section{Conclusion}

Co-precipitation method has been successfully carried out to synthesize nano sized iron oxide at a relatively low temperature. XRD pattern confirmed the rhombohedral (hexagonal) structure of $\alpha-\mathrm{Fe}_{2} \mathrm{O}_{3}$. The crystalline size of iron oxides particles was found to be $16.55 \mathrm{~nm}$. The as-synthesized iron oxide nanoparticles was examined for morphological details by SEM which confirmed almost round shape and nano-powders were found to be less agglomerate. The observed peaks in EDX spectrum confirmed the presence of Fe \& $\mathrm{O}$ and the absence of impurities in the prepared $\mathrm{Fe}_{2} \mathrm{O}_{3}$. The presence of $\mathrm{Fe}-\mathrm{O}$ bond and its stretching vibration mode was confirmed by FTIR data. Langmuir isotherm model describes the adsorption data well compared to Freundlich, D-RK and FH models. From PFO, PSO, Elovich adsorption-reaction models, PSO fits well and IPD adsorption-diffusion models fail to fit and the line also will not pass through the origins. This means that the reaction is under control of adsorption-reaction model. The obtained maximum sorption capacity for the sorbent was 70.422 $\mathrm{mg} / \mathrm{g}$ and $83.94 \%$ of $\mathrm{Pb}(\mathrm{II})$ was liberated during desorption studies.

\section{Acknowledgements}

Authors are great full to the management of Adama Science and Technology University for providing financial support towards this research work. The author acknowledges Mr. Yilkal Dessie for software support and Dr. Senthilkumar Subramanian for characterization support.

\section{Conflicts of Interest}

The authors declare no conflicts of interest regarding the publication of this paper. 


\section{References}

[1] Kumari, M., Pittman Jr., C.U. and Mohan, D. (2015) Heavy Metals [Chromium (VI) and Lead (II)] Removal from Water Using Mesoporous Magnetite $\left(\mathrm{Fe}_{3} \mathrm{O}_{4}\right)$ Nanospheres. Journal of Colloid Interface Science, 442, 120-132. https://doi.org/10.1016/j.jcis.2014.09.012

[2] Bhatia, M., Satish Babu, R., Sonawane, S.H., Gogate, P.R., Girdhar, A., Reddy, E.R. and Pola, M. (2017) Application of Nanoadsorbents for Removal of Lead from Water. International Journal of Environmental Science and Technology, 14, 1135-1154. https://doi.org/10.1007/s13762-016-1198-6

[3] El-Sayed, M.A. (2001) Some Interesting Properties of Metals Confined in Time and Nanometer Space of Different Shapes. Accounts of Chemical Research, 34, 257-264. https://doi.org/10.1021/ar960016n

[4] Lata, S., Singh, P.K. and Samadder, S.R. (2015) Regeneration of Adsorbents and Recovery of Heavy Metals: A Review. International Journal of Environmental Science and Technology, 12, 1461-1478. https://doi.org/10.1007/s13762-014-0714-9

[5] Ding, C., Cheng, W., Sun, Y. and Wang, X. (2015) Novel Fungus- $\mathrm{Fe}_{3} \mathrm{O}_{4}$ Bio-Nanocomposites as High Performance Adsorbents for the Removal of Radionuclides. Journal of Hazardous Materials, 295, 127-137.

https://doi.org/10.1016/j.jhazmat.2015.04.032

[6] Wang, J., Zheng, S., Shao, Y., Liu, J., Xu, Z. and Zhu, D. (2010) Amino-Functionalized $\mathrm{Fe}_{3} \mathrm{O}_{4} @ \mathrm{SiO}_{2}$ Core-Shell Magnetic Nanomaterial as a Novel Adsorbent for Aqueous Heavy Metals Removal. Journal of Colloid and Interface Science, 349, 293-299. https://doi.org/10.1016/j.jcis.2010.05.010

[7] Vijaya BhaskarReddy, A., et al. (2016) Recent Progress on Fe-Based Nanoparticles: Synthesis, Properties, Characterization and Environmental Applications. Journal of Environmental Chemical Engineering, 4, 3537-3553.

https://doi.org/10.1016/j.jece.2016.07.035

[8] Deliyanni, E.A., Lazaridis, N.K., Peleka, E.N. and Matis, K.A. (2004) Metals Removal from Aqueous Solution by Iron-Based Bonding Agents. Environmental Science and Pollution Research International, 11, 18-21.

https://doi.org/10.1065/espr2003.08.168

[9] Hu, J., Chen, G.H. and Lo, I.M.C. (2006) Selective Removal of Heavy Metals from Industrial Wastewater Using Maghemite Nanoparticle: Performance and Mechanisms. Journal of Environmental Engineering, 132, 709-715. https://doi.org/10.1061/(ASCE)0733-9372(2006)132:7(709)

[10] Chen, Y.H. and Li, F.A. (2010) Kinetic Study on Removal of Copper (II) Using Goethite and Hematite Nano-Photocatalysts. Journal of Colloid and Interface Science, 347, 277-281. https://doi.org/10.1016/j.jcis.2010.03.050

[11] Li, L., Fan, M.H., Brown, R.C., Leeuwen, J.H.V., Wang, J.J., Wang, W.H., Song, Y.H. and Zhang, P.Y. (2006) Synthesis, Properties, and Environmental Applications of Nanoscale Iron-Based Materials: A Review. Comments on Inorganic Chemistry, 27, 1-32. https://doi.org/10.1080/02603590500496721

[12] Zawrah, M.F., El Shereefy, E.S.E., Khudir, A.Y. and Khudir, A.Y. (2018) Reverse Precipitation Synthesis of $\leq 10 \mathrm{~nm}$ Magnetite Nanoparticles and Their Application for Removal of Heavy Metals from Water. Silicon. https://doi.org/10.1007/s12633-018-9841-0

[13] Park, J., An, K.J., Hwang, Y.S., Park, J.G., Noh, H.J., Kim, J.Y., Park, J.H., Hwang, N.M. and Hyeon, T. (2004) Ultra-Large-Scale Syntheses of Mono-Dispersed Nano- 
crystals. Nature Materials, 3, 891-895. https://doi.org/10.1038/nmat1251

[14] Li, X., Liu, Y., Zhang, C.L., Wen, T., Zhuang, L., Wang, X.X., Song, G., Chen, D.Y., Ai, Y.J., Hayat, T. and Wang, X.K. (2018) Porous $\mathrm{Fe}_{2} \mathrm{O}_{3}$ Microcubes Derived from Metal Organic Frameworks for Efficient Elimination of Organic Pollutants and Heavy Metal Ions. Chemical Engineering Journal, 336, 241-252. https://doi.org/10.1016/j.cej.2017.11.188

[15] Abebe, B., Taddesse, A.M., Kebede, T., Teju, E. and Diaz, I. (2017) Fe-Al-Mn Ternary Oxide Nanosorbent: Synthesis, Characterization and Phosphate Sorption Property. Journal of Environmental Chemical Engineering, 5, 1330-1340. https://doi.org/10.1016/j.jece.2017.02.026

[16] Muneeb, M., Khattak, U.R., Zahoor, M., Muhammad, B., Khan, F.A., Ullah, R. and AbdEI-Salam, N.M. (2017) Removal of Heavy Metals from Drinking Water by Magnetic Carbon Nanostructures Prepared from Biomass. Journal of Nanomaterials, 14, 1-10. https://doi.org/10.1155/2017/5670371

[17] Lassoued, A., Dkhil, B., Gadri, A. and Ammar, S. (2017) Control of the Shape and Size of Iron Oxide $\left(\mathrm{a}-\mathrm{Fe}_{2} \mathrm{O}_{3}\right)$ Nanoparticles Synthesized through the Chemical Precipitation Method. Results in Physics, 7, 3007-3015. https://doi.org/10.1016/j.rinp.2017.07.066

[18] Sharma, P., Kumar, R., Chauhan, S., Singh, D. and Chauhan, M.S. (2014) Facile Growth and Characterization of $\alpha-\mathrm{Fe}_{2} \mathrm{O}_{3}$ Nanoparticles for Photocatalytic Degradation of Methyl Orange. Journal of Nanoscience and Nanotechnology, 14, 6153-6157. https://doi.org/10.1166/jnn.2014.8734

[19] Ordoukhanian, J., Karami, H. and Nezhadali, A. (2016) One Step Paired Electrochemical Synthesis of Iron and Iron Oxide Nanoparticles. Materials Science-Poland, 34, 655-658. https://doi.org/10.1515/msp-2016-0090

[20] Umar, A., Ahmad, R., Hwang, S.W., Kim, S.H., Al-Hajry, A. and Hahn, Y.B. (2014) Development of Highly Sensitive and Selective Cholesterol Biosensor Based on Cholesterol Oxidase Co-Immobilized with $\alpha-\mathrm{Fe}_{2} \mathrm{O}_{3}$ Micro-Pine Shaped Hierarchical Structures. Electrochimica Acta, 135, 396-403. https://doi.org/10.1016/j.electacta.2014.04.173

[21] Peer, F.E., Bahramifar N. and Younesi, H (2018) Removal of Cd(II), Pb(II) and $\mathrm{Cu}$ (II) Ions from Aqueous Solution by Polyamidoamine Dendrimer Grafted Magnetic Graphene Oxide Nanosheets. Journal of the Taiwan Institute of Chemical Engineers, 87, 225-240. https://doi.org/10.1016/j.jtice.2018.03.039

[22] Zolfaghari, G., Esmaili-Sari, A., Anbia, M., Younesi, H., Amirmahmoodi, S. and GhafariNazari, A. (2011) Taguchi Optimization Approach for $\mathrm{Pb}$ (II) and $\mathrm{Hg}$ (II) Removal from Aqueous Solutions Using Modified Mesoporous Carbon. Journal of Hazardous Materials, 192, 1046-1055. https://doi.org/10.1016/j.jhazmat.2011.06.006

[23] Shahmirzadi, M.M.A., Hosseini, S.S., Luo, J. and Ortiz, I. (2018) Significance, Evolution and Recent Advances in Adsorption Technology, Materials and Processes for Desalination, Water Softening and Salt Removal. Journal of Environmental Management, 215, 324-344. https://doi.org/10.1016/j.jenvman.2018.03.040

[24] Dil, E.A., Ghaedi, M., Ghezelbash, G.R., Asfaram, A. and Purkait, M.K. (2017) Highly Efficient Simultaneous Biosorption of $\mathrm{Hg}^{2+}, \mathrm{Pb}^{2+}$ and $\mathrm{Cu}^{2+}$ by Live Yeast Yarrowialipolytica 70562 Following Response Surface Methodology Optimization: Kinetic and Isotherm Study. Journal of Industrial and Engineering Chemistry, 48, 162-172. https://doi.org/10.1016/j.jiec.2016.12.035

[25] Dil, E.A., Ghaedi, M.A. Asfaram, A., Hajati S., Mehrabi, F. and Goudarzi, A. (2017) Preparation of Nanomaterials for the Ultrasound-Enhanced Removal of $\mathrm{Pb}^{2+}$ Ions 
and Malachite Green Dye: Chemometric Optimization and Modeling. Ultrasonics Sonochemistry, 34, 677-691. https://doi.org/10.1016/j.ultsonch.2016.07.001

[26] Asfaram, A., Ghaedi, M. and Ghezelbash, G.R. (2016) Biosorption of $\mathrm{Zn}^{2+}, \mathrm{Ni}^{2+}$ and $\mathrm{Co}^{2+}$ from Water Samples onto Yarrowialipolytica ISF7 Using a Response Surface Methodology and Analyzed by Inductively Coupled Plasma Optical Emission Spectrometry (ICP-OES). RSC Advances, 6, 23599-23610.

https://doi.org/10.1039/C5RA27170C

[27] Maji S., Ghosh, A., Gupta K., Ghosh, A., Ghorai, U., Santra, A., Sasikumar, P., Ghosh, U. and Chand P. (2018) Efficiency Evaluation of Arsenic(III) Adsorption of Novel Grapheme Oxide@Iron-Aluminium Oxide Composite for the Contaminated Water Purification. Separation and Purification Technology, 197, 388-400.

https://doi.org/10.1016/j.seppur.2018.01.021

[28] Huan, C., Lia, T., Zhanga, L., Wanga, R., Jianga, F. and Chenb, J., (2015) Pb(II) Adsorption on Magnetic g- $\mathrm{Fe}_{2} \mathrm{O}_{3}$ /Titanate Nanotubes Composite. Journal of Environmental Chemical Engineering, 3, 2022-2030.

https://doi.org/10.1016/j.jece.2015.07.010

[29] Ho, S.H., Wang, D., Wei, Z., Chang, J.S. and Ren, N. (2018) Lead Removal by a Magnetic Biochar Derived from Persulfate-ZVI Treated Sludge Together with One-Pot Pyrolysis. Bioresource Technology, 247, 463-470.

https://doi.org/10.1016/j.biortech.2017.09.125 